TITLE:

\title{
Inhibition of fatty acid oxidation activates transforming growth factor-beta in cerebrospinal fluid and decreases spontaneous motor activity.
}

\section{AUTHOR(S):}

Fujikawa, Teppei; Fujita, Ryo; Iwaki, Yoko; Matsumura, Shigenobu; Fushiki, Tohru; Inoue, Kazuo

\section{CITATION:}

Fujikawa, Teppei ...[et al]. Inhibition of fatty acid oxidation activates transforming growth factor-beta in cerebrospinal fluid and decreases spontaneous motor activity.. Physiology \& behavior 2010, 101(3): 370-375

\section{ISSUE DATE:}

2010-10-05

URL:

http://hdl.handle.net/2433/128898

\section{RIGHT:}

(c) 2010 Elsevier Inc.; This is not the published version. Please cite only the published version.; この論文は出版社版でありません。引用の際に は出版社版をご確認ご利用ください。 
1 Title: Inhibition of fatty acid oxidation activates transforming growth factor-beta in

2 cerebrospinal fluid and decreases spontaneous motor activity

3

4 Authors:

5 Teppei Fujikawa ${ }^{1,2}$, Ryo Fujita ${ }^{1}$, Yoko Iwaki ${ }^{1}$, Shigenobu Matsumura ${ }^{1}$, Tohru Fushiki ${ }^{1}$, 6 Kazuo Inoue ${ }^{1}$

7

8 Affiliations:

9 1, Laboratory of Nutrition Chemistry, Division of Food Science and Biotechnology,

10 Graduate School of Agriculture, Kyoto University

11

12 2, Current address; Department of Internal Medicine, Division of Hypothalamic, 13 Research, The University of Texas Southwestern Medical Center, Dallas, TX, 75390, 14 USA.

15

16 Corresponding Author: Kazuo Inoue, Laboratory of Nutrition Chemistry, Division of 17 Food Science and Biotechnology, Graduate School of Agriculture, Kyoto University, 18 Kyoto 606-8502, Japan, +81 75753 6263, ashlaoh@kais.kyoto-u.ac.jp 19 


\section{Abstract}

We have previously reported that transforming growth factor (TGF)-beta in

3 the cerebrospinal fluid (CSF) is involved in the mechanism underlying the regulation of

4 spontaneous motor activity (SMA) by the central nervous system after exercise.

5 However, it remained unclear what physiological condition triggers the activation of

6 TGF-beta. We hypothesized that the shortage of energy derived from fatty acid (FA)

7 oxidation observed in the early phase of exercise activated TGF-beta in the CSF. To test

8 this hypothesis, we investigated whether mercaptoacetate (MA), an inhibitor of FA

9 oxidation, could induce an activation of TGF-beta in the CSF and a decrease in SMA.

10 Intraperitoneal (i.p.) administration of MA activated TGF-beta in CSF in rats and

11 depressed SMA; 2-deoxyglucose, an inhibitor of carbohydrate oxidation, on the other hand, depressed SMA but failed to activate CSF TGF-beta. Intracisternal administration

13 of anti-TGF-beta antibody abolished the depressive effect of MA on SMA. We also

14 found that the depression of SMA and the activation of TGF-beta in the CSF by i.p. MA

15 administration were eliminated by vagotomy. Our data suggest that TGF-beta in the

16 CSF is activated by the inhibition of FA oxidation via the vagus nerve and that this

17 subsequently induces depression of SMA. 
2 Keywords

3 TGF-beta, exercise, fatty acid oxidation, vagotomy, mercaptoacetate, 2-deoxyglucose 


\section{Introduction}

We previously demonstrated that transforming growth factor (TGF)-beta in

3 the cerebrospinal fluid (CSF) was activated after exercise and that intracisternal (i.c.)

4 administration of TGF-beta decreased spontaneous motor activity (SMA) in rodents

5 [20,42]. These results indicated that activated TGF-beta in the CSF was one of the

6 components in the system responsible for SMA depression after exercise. However, it

7 remained unclear what physiological condition leads to activation of TGF-beta in the

8 CSF.

9

The fact that TGF-beta in the CSF is activated during moderate intensity exercise [20] allows us to assume that certain metabolic alterations observed in exercise

11 trigger the activation of TGF-beta in the CSF. During the transition from a sedentary

12 state to the early phase of exercise, several catabolic alterations occur [37] in response

13 to a drastic increase in energy expenditure [21]. Therefore, we focused on energy

14 metabolism in the early phase of exercise, which we regarded as that period from the

15 commencement of exercise until the achievement of a metabolic equilibrium state at a

16 particular exercise intensity, which usually seems to be $10-20$ minutes $[17,21]$. The 
1 main energy supply resources in exercise are carbohydrate and fat $[7,8]$. Because of the

2 immediate responsiveness of glycogenolysis to increased energy demand [8],

3 carbohydrate oxidation can rapidly increase in the early phase of exercise [17,21]. Fatty

4 acid (FA) oxidation, on the other hand, increases gradually [17], because the

5 responsiveness of FA mobilization from fat depots depends on triacylglycerol lipolysis.

6 Lipolytic activity in adipose tissues during exercise is mediated by the autonomic

7 nervous system and hormones; additionally, the delivery of fatty acids from adipose

8 tissue to working muscles is mediated by increased blood flow velocity, which is also

9 regulated by the autonomic nervous system and hormones [2,15,19]. Energy production

10 from FA oxidation in the early phase of exercise is thus relatively inadequate until FA

11 mobilization reaches a sufficient extent. Indeed, intravenous lipid infusion can increase

12 FA oxidation in the early phase of exercise [33]. In addition, especially in this phase of

13 exercise, FA levels in the blood can decrease [12]. These observations suggest that the

14 extent of FA mobilization in the early phase of exercise is insufficient for the capacity

15 for FA oxidation, or that, in other words, a relative shortage of energy derived from FA

16 oxidation occurs in this phase of exercise. In the normal physiological state, such a 
1 shortage is observed only in the early phase of exercise.

3 oxidation can trigger the activation of TGF-beta in the CSF. Indeed, intracisternal

4 administration of TGF-beta induces a decrease in SMA [20] and an increase in FA

5 oxidation [42]. The role of TGF-beta in the CSF is therefore counter-regulatory in

6 response to a relatively decreased FA oxidation level. To test our hypothesis, we

7 investigated SMA and TGF-beta levels in CSF in rats after intraperitoneal (i.p)

8 administration of mercaptoacetate (MA), an FA oxidation inhibitor [3]. Administration

9 of MA can mimic the physiological condition observed as the relative shortage of

10 energy derived from FA oxidation in the early phase of exercise. To compare the effect

11 of inhibition of fatty acid oxidation with that of the inhibition of carbohydrate oxidation,

12 we also analyzed activated CSF TGF-beta concentrations and SMA after i.p.

13 administration of 2-deoxyglucose (2-DG), a carbohydrate oxidation inhibitor [41]. We

14 found that both metabolic inhibitors decreased SMA in rats, although only MA, the FA

15 oxidation inhibitor, activated TGF-beta in the CSF. We also demonstrated that

16 TGF-beta in the CSF is responsible for decreased SMA through the inhibition of FA 
1 oxidation.

2 


\section{2. Materials \& Methods}

2

4 Japan) were used. All animals were maintained under controlled environmental

5 conditions $\left(22^{\circ} \mathrm{C} \pm 0.5^{\circ} \mathrm{C}, 12\right.$-h light-dark cycle), and fed normal chow (MF, Oriental

6 Yeast, Tokyo, Japan) and water ad libitum for at least 1 week prior to their use in

7 experiments. All animals were treated humanely, as outlined in the National Research

8 Council's guide for the Care and Use of Laboratory Animals (Kyoto University Animal

9 Care Committee, according to NIH \#86-23, revised 1985). In addition, all procedures were approved by the Kyoto University Animal Care and Use Committee. All

11 experiments were started $2 \mathrm{~h}$ after the onset of the dark cycle.

2.2 Determination of spontaneous motor activity after administration of metabolic inhibitors administered i.p. to rats. To determine appropriate experimental conditions, we tested 
1200,400 , and $600-\mu \mathrm{mol} / \mathrm{kg}$ body weight (B.W.) doses of MA, and 200, 400, and

$2600-\mathrm{mg} / \mathrm{kg} \mathrm{B.W}$. doses of 2-DG. Time-course changes in SMA were measured over 1, 2,

3 and 3-h durations for both MA and 2-DG. We selected doses of $400 \mu \mathrm{mol} / \mathrm{kg} \mathrm{B}$.W. for

4 MA and $400 \mathrm{mg} / \mathrm{kg} \mathrm{B.W}$. for 2-DG, and a 2-h duration for all subsequent experiments.

5 MA causes decreased energy production from FA oxidation [28] by inhibiting acyl-CoA

6 dehydrogenase activity [3]. 2-DG induces a decrease in glucose oxidation through the

7 competitive inhibition of phosphohexose isomerase [41]. MA and 2-DG were dissolved

8 in sterile saline (Otsuka Pharmaceutical, Tokyo, Japan), and the same volume of saline

9 was administered i.p. to rats in a control group. The rats were then deprived of food.

10 After $2 \mathrm{~h}$, the rats were moved from their home cage to a test cage $(25 \times 38 \times 17.5 \mathrm{~cm})$.

11 SMA was measured using an infrared ray sensor (Muromachi Kikai, Tokyo, Japan) as

12 described previously [42].

14 2.3 CSF Collection and determination of the level of active TGF-beta in the CSF 
1 anesthetized by administration of urethane (i.p., $1.5 \mathrm{~g} / \mathrm{kg} \mathrm{B.W.)} \mathrm{and} \mathrm{CSF} \mathrm{was} \mathrm{collected.}$

2 CSF collection and TGF-beta level assay were as described previously [27]. Briefly,

3 CSF was collected from the cisterna magna after puncturing the atlantooccipital

4 membrane with a $26 \mathrm{G}$ needle fitted to the tip of a micropipette and centrifuged at 2000

$5 g$ at $4{ }^{\circ} \mathrm{C}$. The supernatant was then collected and stored at $-70^{\circ} \mathrm{C}$ until TGF-beta assay.

6 TGF-beta concentrations in CSF were determined with a bioassay using

7 TGF-beta-responsive mink lung epithelial cells (TMLCs) constitutively transfected with

8 a TGF-beta-responsive human plasminogen activator inhibitor-1 promoter-luciferase

9 construct (kindly provided by Dr. M. Abe, Department of Nanomedicine, Tokyo

10 Medical and Dental University, Tokyo, Japan, and Dr. D. Rifkin, Department of Cell

11 Biology, NYU Medical Center, New York, NY, USA) [1]. All samples were diluted

12 with Dulbecco's modified Eagle's medium (DMEM) containing $0.1 \%$ bovine serum

13 albumin (BSA). TMLCs suspended in DMEM with $10 \%$ fetal bovine serum were

14 seeded onto 96-well plates (10,000 cells/well) and allowed to attach for $6 \mathrm{~h}$; thereafter,

15 the medium was replaced with $100 \mu \mathrm{L}$ of sample solution. After a further $16 \mathrm{~h}$,

16 luciferase activity was measured using a luciferase assay system (Promega, Ann Arbor, 
$1 \mathrm{MI}$ ), according to the manufacturer's instructions. Levels of active TGF-beta in CSF are

2 expressed as relative luminescence units (RLU). The average RLU value in control

3 groups was defined as $100 \%$.

4

5

2.4 Intracisternal administration of anti-TGF-beta antibody

6 Rats were anesthetized by i.p. injection of $1 \mathrm{mg} / \mathrm{kg}$ pentobarbital sodium

7 (Dainippon Seiyaku, Osaka, Japan) and placed in a stereotaxic frame adapted for rat

8 surgery. Subsequently, the skull was exposed and a hole drilled to insert a cannula

9 (24G). Coordinates for placing the cannula in the cisterna magna were as follows: AP,

$10-2.5$; ML, 0.0; and DV, -7.9 from the lambda; angle, $-32^{\circ}$ posteriorly. Rats were

11 allowed 1 week to recover, and only animals with body weights greater than before

12 surgery were used. On the day of an experiment, $5 \mu \mathrm{g}$ anti-TGF-beta or control

13 preimmune antibodies (R\&D Systems, Minneapolis, MN) dissolved in $10 \mu \mathrm{L}$ artificial

14 cerebrospinal fluid (a-CSF; $140 \mathrm{mM} \mathrm{NaCl}, 3.35 \mathrm{mM} \mathrm{KCl}, 1.2 \mathrm{mM} \mathrm{Na}_{2} \mathrm{PO}_{4}, 0.3 \mathrm{mM}$

$15 \mathrm{NaH}_{2} \mathrm{PO}_{4}$, and $0.10 \%$ fatty-acid-free $\mathrm{BSA}$ ) were administered i.c. Immediately

16 afterwards, MA (400 $\mu \mathrm{mol} / \mathrm{kg} \mathrm{B.W.)} \mathrm{or} \mathrm{2-DG} \mathrm{(400} \mathrm{mg/kg} \mathrm{B.W.)} \mathrm{was} \mathrm{i.p.} \mathrm{administered.}$ 
1 Saline was administered as a control.

2

3

2.5 Vagotomy

4

After anesthetization with an i.p. injection of $1 \mathrm{mg} / \mathrm{kg}$ pentobarbital sodium,

5 rats were vagotomized as described by Li and Anderson [24]. In brief, a 5-cm midline

6 incision was made in the abdomen to expose the stomach and lower esophagus.

7 Thereafter, the bilateral vagal trunks were exposed and cut. A similar procedure was

8 carried out during sham surgery, except that the vagal trunks were not damaged. Rats

9 were allowed 2 weeks to recover from surgery. Because vagotomy decreases food

10 intake for 2 weeks [24], operations were judged successful in rats whose food intake

11 decreased for at least 2 weeks. Rats that failed to regain pre-operation body weight were

12 excluded from subsequent experiments. There was an interval of at least 1 week

13 between each SMA experiment. Firstly, SMA was determined after the i.p.

14 administration of saline, and then the effects of i.p. administration of MA (400 $\mu \mathrm{mol} / \mathrm{kg}$

15 B.W.) and 2-DG (400 mg/kg B.W.) on SMA were determined. Finally, SMA was

16 determined in the untreated state. This sequence of experiment was not randomized, but 
1 we confirmed the last administration of inhibitors did not affect the next basal counts of

2 SMA after one-week interval. CSF was collected from freshly vagotomized rats after a

32 week recovery period, as described above.

4

\section{$5 \quad 2.6$ Statistical analysis}

All data are expressed as mean \pm S.E.M. Data in Figures 1B, 1D, 2, and 5

7 were analyzed using Student's $t$ test. Data in Figure 3A were analyzed using a two-way

8 analysis of variance (ANOVA), and there was a significant interaction between i.c. and

9 i.p. administration. The data were then analyzed using one-way ANOVA, followed by

10 multiple comparison testing using a post-hoc Tukey's multiple comparison test. Data in

11 Figure 3B were analyzed using a two-way ANOVA, and there was no significant

12 interaction between i.c. and i.p. administration. The data were then analyzed using a

13 Student's $t$ test in the same factor. Data in Figure 4 were analyzed using a one-way

14 ANOVA, followed by multiple comparison testing using a post-hoc Tukey's multiple comparison test. $\mathrm{P}$ values of $5 \%$ or less were considered statistically significant. Prism

164 for Mac (GraphPad Software, CA, USA) was used for statistical analysis. 


\section{3. Results}

23.1 Effect of i.p. administration of MA and 2-DG on SMA

Firstly, we investigated whether the inhibition of FA oxidation depressed

4 SMA similarly to exercise [20] or TGF-beta i.c. administration [20,42]. We carried out

5 SMA measurements after inhibition of FA oxidation by MA i.p. administration.

6 Time-course changes in SMA over $60 \mathrm{~min}, 2 \mathrm{~h}$ after i.p. administration of MA (400

$7 \mu \mathrm{mol} / \mathrm{kg}$ B.W.), are presented in Figure 1A. The cumulative SMA value in the MA

8 group was significantly lower than that in the saline group (Fig. $1 \mathrm{~B}, \mathrm{P}=0.0036$ ). To

9 compare the effect of MA with another metabolic inhibitor, we tested whether 2-DG

10 alters SMA in rats. Time-course changes in SMA over $60 \mathrm{~min}, 2 \mathrm{~h}$ after i.p.

11 administration of 2-DG (400 mg/kg B.W.), are presented in Figure 1C. The cumulative

12 SMA value in the 2-DG group was significantly lower than that in the saline group (Fig.

13 1D, $\mathrm{P}<0.0001)$. 
1 next measured TGF-beta levels in CSF after MA or 2-DG administration. Two hours

2 after i.p. administration, the TGF-beta level in the CSF of rats given MA (400 $\mu \mathrm{mol} / \mathrm{kg}$

3 B.W.) was significantly higher than that in rats given saline (Fig. $2 \mathrm{~A}, \mathrm{P}=0.0295$ ). In

4 contrast, there was no significant difference between TGF-beta levels in the CSF $2 \mathrm{~h}$

5 after i.p. administration in rats given 2-DG (400 mg/kg B.W.) and rats given saline (Fig.

$62 \mathrm{~B}, \mathrm{P}=0.6153)$.

7

83.3 Effect of i.c. administration of anti-TGF-beta antibody on SMA after i.p.

9 administration of $M A$ and $2-D G$

To determine whether increased TGF-beta in the CSF is required for

11 decreased SMA after administration of MA, we tested whether i.c. administered

12 anti-TGF-beta antibody eliminated the effect of MA on SMA. Previously, we had

13 demonstrated that i.c. anti-TGF-beta antibody administration completely abolished the

14 physiological effect of TGF-beta in the CSF [18, 19]. There was a statistically

15 significant interaction between i.c. anti-TGF-beta antibody administration and i.p. MA

16 administration (Fig. $3 \mathrm{~A}, \mathrm{P}=0.026$ ). The cumulative SMA value over $60 \mathrm{~min}$ in the 
1 control group that received preimmune antibody was significantly lower than that in the

2 group that had received the anti-TGF-beta antibody (Fig $3 \mathrm{~A}, \mathrm{P}<0.05$ ). There was no

3 significant interaction, however, between i.c. anti-TGF-beta administration and i.p.

4 2-DG administration (Fig. 3B, $\mathrm{P}=0.2973$ ). In both the preimmune and anti-TGF-beta

5 antibody-treated groups, cumulative SMA values over 60 min were significantly lower

6 than that in the i.p. saline group (Fig. 3B, preimmune antibody, $\mathrm{P}=0.0339$;

7 anti-TGF-beta, $\mathrm{P}=0.00234)$.

8

93.4 Effect of vagotomy on SMA after i.p. administration of MA and 2-DG

To determine whether the vagus nerve is involved in the effect of MA on

11 SMA, we tested whether vagotomy reverses the depression in SMA after i.p. MA

12 administration. In vagotomized rats, there was no significant difference between

13 cumulative SMA values in the i.p. MA and i.p. saline groups (Fig. 4A, P > 0.05). SMA

14 after the i.p. administration of 2-DG was significantly lower than that in the i.p. saline

15 group (Fig. 4A, $\mathrm{P}<0.01$ ). In sham-operated rats, respective cumulative SMA values

16 for the MA and 2-DG groups were significantly lower than that of the saline group (Fig. 
1 4B, MA, $\mathrm{P}<0.05 ; 2-\mathrm{DG}, \mathrm{P}<0.0001 w)$. In the sedentary state, the cumulative SMA

2 values of vagotomized and sham operated rats were $11030 \pm 758$ and $15120 \pm 381.5$,

3 respectively $(\mathrm{P}<0.001$ by Student's $t$ test).

4

53.5 Effect of vagotomy on CSF TGF-beta levels after intraperitoneal administration of

$6 \quad M A$

Finally, we tested whether vagotomy reversed the increase in TGF-beta

8 produced by i.p. MA administration. In vagotomized rats, there was no significant

9 difference between CSF TGF-beta levels in the i.p. MA and i.p. saline groups (Fig. 5A,

$10 \mathrm{P}=0.371)$. In sham-operated rats, the TGF-beta level in the CSF was significantly

11 higher in animals that had received i.p. MA than in those that had received saline (Fig.

$125 \mathrm{~B}, \mathrm{P}=0.0467)$. In the untreated state, there was no significant difference between

13 TGF-beta levels in the CSF of vagotomized and sham-operated rats (data not shown). 


\section{4. Discussion}

3 TGF-beta in the CSF via the vagus nerve. Decreased SMA after exercise might prevent

4 further undesirable energy exhaustion in animals and allow restoration of energy stores.

5 The brain collects peripheral metabolic information and coordinates animal behavior to

6 maintain energy homeostasis $[29,36]$. Thus, the decrease in SMA after exercise may not

7 only result from the exhaustion of energy stores and potential damage in peripheral

8 tissues but might also reflect a process that is more actively regulated by the CNS. The

9 entire mechanism by which SMA is decreased after exercise by the CNS is still poorly

10 understood; however, our reports $[14,20,21,42]$ together with the results obtained in this

11 study highlight that TGF-beta in the CSF plays a crucial role in the mechanism

12 underlying the regulation of behavior by the CNS after exercise.

It has previously been unclear what physiological conditions trigger the

14 activation of TGF-beta in the CSF during exercise. We focused on the unique metabolic

15 alteration which is observed as a relative shortage of energy derived from FA oxidation

16 in the early phase of exercise $[12,33]$. We then hypothesized that the shortage of energy 
1 derived from FA oxidation activated TGF-beta in the CSF. As expected, the inhibition

2 of FA oxidation activated TGF-beta in the CSF (Fig. 2). To rule out of the possibility

3 that the activation of TGF-beta in the CSF by inibition of FA oxidation is observed only

4 in MA administration, we measured TGF-beta levels in the CSF after i.p. administration

5 of etomoxir, another inhibitor of FA oxidation. Etomoxir also activated TGF-beta in the

6 CSF (Supplement Figure 1). Additionally a decrease in locomotor activity by

7 administration of etomoxir is already shown [16]. Therefore, the activation of TGF-beta

8 in the CSF and the subsequent decrease in SMA surely result from the inihibtion of FA

9 oxidation. The inhibition of carbohydrate oxidation, on the other hand, did not activate

10 TGF-beta in the CSF (Fig 2). Taking into consideration that i.c. administration of

11 TGF-beta increases FA oxidation [42], TGF-beta in the CSF is involved in a

12 counter-regulatory system that responds to decreased FA oxidation. We showed that i.c.

13 administration of anti-TGF-beta antibody prevented the depressive effect of i.p.

14 administration of MA on SMA (Fig. 3). This indicates that the activation of TGF-beta in

15 the CSF is required for the depression of SMA induced by inhibition of FA oxidation.

16 Taken together, our data suggest that the physiological condition that activates 
1 TGF-beta in the CSF during exercise is likely the shortage of energy derived from FA

2 oxidation observed in the early phase of exercise.

3

It has been reported that the increased food intake observed following MA

4 administration [35] is eliminated by vagotomy [23]. MA inhibits acyl-CoA

5 dehydrogenase in the liver [3], decreases membrane potential and induces

6 depolarization in hepatocytes [6], and leads to increased afferent activity in the hepatic

7 vagus branch [26]. These observations suggest that information concerning deficient

8 production of energy from FA oxidation is transmitted to the brain via the vagus nerve.

9 Vagotomy eliminated the depressive effect of i.p. administration of MA on SMA

10 (Fig. 4A), but not that of 2-DG (Fig. 4B). Intraperitoneal MA administration to

11 vagotomized rats did not activate TGF-beta in the CSF (Fig. 5A). We are unable to rule

12 out the possibility that ablation of the effect of MA on SMA by vagotomy resulted from

13 the intrinsic effects of the vagotomy itself, which also affected SMA in the sedentary

14 state. However, SMA values (Fig. 4) did appear to be inversely correlated with the

15 concentration of active TGF-beta in CSF (Fig. 5). These data strongly support the

16 contention that the vagus nerve is important in the activation of TGF-beta induced by 
1 inhibition of FA oxidation.

2

It is unclear how the liver detects changes in FA oxidation levels and

transmits signals to the brain via the vagus nerve. Because either administration of fatty

4 acid or inhibitors of fatty acid oxidation, but not glucose, alters plasma membrane

5 potential in hepatic cells in vitro and vivo $[6,26,34]$, it is possible that efferent sensory

6 neurons directly sense an alternation in fatty acid oxidation. A report that the neuronal

7 sensing pathway of inhibition of FA oxidation is different from that of glucose

8 oxidation [30] also supports this notion. Inhibition of FA oxidation leads to reduction in

9 adenosine triphosphate (ATP)/ adenosine diphosphate (ADP) ratio in the liver $[13,18]$,

10 on the other hand, a single administration of 2-DG does not decrease ATP/ADP ratio in

11 the liver [38]. Then it is another explanation that consequence of reduction in ATP/ADP

12 ratio induced by inhibition of FA oxidation results in changes in hepatic plasma

13 membrane potential, which might be transmitted to sensory neurons by yet-unidentified

14 mechanisms. Further studies are necessary to elucidate how information concerning

15 deficient FA oxidation is transmitted from the liver to the brain. 
1 conditions having shown the mechanism underlying the activation of TGF-beta

$2[5,9,22,44]$, to the best of our knowledge there is no clear understanding of the

3 TGF-beta activation mechanism in the CSF of rodents under in vivo physiological

4 conditions. TGF-beta is widely distributed in the brain [39], and is expressed by various

5 cell types [5]. The TGF-beta receptor is also widely expressed in the brain [4].

6 Therefore, from an immunohistochemical point of view, the particular location within

7 the brain where TGF-beta is activated and responsible for depressing SMA and

8 enhancing FA oxidation cannot be determined. However, we previously demonstrated

9 that i.c. TGF-beta administration activates hypothalamic noradrenergic neurons [14],

10 which project from the vicinity of the nucleus of the solitary tract (NTS). This suggests

11 that TGF-beta can affect the NTS. Visceral information is transmitted mainly to the

12 NTS via the vagus nerve system $[36,40]$. Therefore, inhibition of FA oxidation may

13 activate TGF-beta via the vagus nerve and the NTS. Intravenous administration of MA

14 induced c-Fos expression in several region including, NTS, hypothalamus, lateral

15 parabrachial nucleus (IPBN), and the central nucleus of amygdala (CNA). [31]. The

16 lesion of NTS, IPBN and CNA abolish the MA-induces appetites feeding behavior. 
$1 \quad[10,30,32]$. Additionally, the finding that MA-induced feeding behavior is abolished in

2 decerebrate rats indictates that the projection from NTS to forebrain is important for the

3 feeding behavior induced by the inhibition of FA oxidation [11]. These reports are

4 consistent with our report that TGF-beta in the brain activates NTS-hypothalamus

5 circuits [14]. Further studies are needed to elucidate the mechanism underlying the

6 activation of TGF-beta in the NTS and the subsequent decrease in SMA. In conclusion, we have demonstrated that i.p. administration of MA, which

8 inhibits FA oxidation, induces decreased SMA in rats. This effect of MA administration

9 is transmitted via the vagus nerve and mediated by TGF-beta in the CSF. Impaired FA

10 oxidation has been reported to lead to decreased SMA [16]. In addition, carnitine is an

11 essential substance for beta-oxidation of FA and a decrease in SMA observed in fasting

12 carnitine-deficient mice [25] can be rescued by carnitine administration [43]. This

13 report also suggests a relationship between a reduction in energy supplied by FA

14 oxidation and a decrease in SMA. Taking other studies into consideration, inhibition of

15 FA oxidation strongly appears to lead to down-regulation of locomotor activity via the

16 liver-vagus nerve-brain system. Our data suggest that TGF-beta in the CSF plays a 
1 crucial role in this mechanism.

2 


\section{Acknowledgement}

2

We thank Ayumi Yamada, Miyaki Takashi, Kayo Mizuno, Ryo Kitaoka, Koji

3 Shimosuka and Mari Takata for experimental support.

4 


\section{References}

3 [1] Abe M, Harpel JG, Metz CN, Nunes I, Loskutoff DJ, Rifkin DB. An assay for 4 transforming growth factor-beta using cells transfected with a plasminogen activator 5 inhibitor-1 promoter-luciferase construct. Anal Biochem 1994; 216: 276-84

6 [2] Bartness TJ, Bamshad M. Innervation of mammalian white adipose tissue: 7 implications for the regulation of total body fat. Am J Physiol 1998; 275: R1399-411

8 [3] Bauche F, Sabourault D, Giudicelli Y, Nordmann J, Nordmann R. Inhibition

9 in vitro of acyl-CoA dehydrogenases by 2-mercaptoacetate in rat liver mitochondria.

10 Biochem J 1983; 215: 457-64

11 [4] Bottner M, Unsicker K, Suter-Crazzolara C. Expression of TGF-beta type II 12 receptor mRNA in the CNS. Neuroreport 1996; 7: 2903-7

13 [5] Bottner M, Krieglstein K, Unsicker K. The transforming growth factor-betas: 14 structure, signaling, and roles in nervous system development and functions. $\mathrm{J}$ 15 Neurochem 2000; 75: 2227-40

16 [6] Boutellier S, Lutz TA, Volkert M, Scharrer E. 2-Mercaptoacetate, an inhibitor 17 of fatty acid oxidation, decreases the membrane potential in rat liver in vivo. Am $\mathbf{J}$ 18 Physiol 1999; 277: R301-5

19 [7] Brooks GA, Mercier J. Balance of carbohydrate and lipid utilization during 20 exercise: the "crossover" concept. J Appl Physiol 1994; 76: 2253-61

21 [8] Brouns F, van der Vusse GJ. Utilization of lipids during exercise in human 22 subjects: metabolic and dietary constraints. Br J Nutr 1998; 79: 117-28

23 [9] Brown PD, Wakefield LM, Levinson AD, Sporn MB. Physicochemical 24 activation of recombinant latent transforming growth factor-beta's 1, 2, and 3. Growth 25 Factors 1990; 3: 35-43

26 [10] Calingasan NY, Ritter S. Lateral parabrachial subnucleus lesions abolish 27 feeding induced by mercaptoacetate but not by 2-deoxy-D-glucose. Am J Physiol 1993; 28 265: R1168-78

29 [11] Darling RA, Ritter S. 2-Deoxy-D-glucose, but not mercaptoacetate, increases 30 food intake in decerebrate rats. Am J Physiol Regul Integr Comp Physiol 2009; 297: 31 R382-6

32 [12] Friedberg SJ, Sher PB, Bogdonoff MD, Estes EH, Jr. The Dynamics Of 33 Plasma Free Fatty Acid Metabolism During Exercise. J Lipid Res 1963; 4: 34-8 
1 [13] Friedman MI, Harris RB, Ji H, Ramirez I, Tordoff MG. Fatty acid oxidation 2 affects food intake by altering hepatic energy status. Am J Physiol 1999; 276: R1046-53

3 [14] Fujikawa T, Matsumura S, Yamada H, Inoue K, Fushiki T. Transforming 4 growth factor-beta in the brain enhances fat oxidation via noradrenergic neurons in the 5 ventromedial and paraventricular hypothalamic nucleus. Brain Res 2007; 1173: 92-101

6 [15] Hodgetts V, Coppack SW, Frayn KN, Hockaday TD. Factors controlling fat 7 mobilization from human subcutaneous adipose tissue during exercise. J Appl Physiol $8 \quad 1991 ; 71: 445-51$

9 [16] Hogberg H, Engblom L, Ekdahl A, Lidell V, Walum E, Alberts P. 10 Temperature dependence of $\mathrm{O} 2$ consumption; opposite effects of leptin and etomoxir on 11 respiratory quotient in mice. Obesity (Silver Spring) 2006; 14: 673-82

12 [17] Holloway GP, Bezaire V, Heigenhauser GJ, Tandon NN, Glatz JF, Luiken 13 JJB, 1996 \#35\}, Bonen A, Spriet LL. Mitochondrial long chain fatty acid oxidation, 14 fatty acid translocase/CD36 content and carnitine palmitoyltransferase I activity in 15 human skeletal muscle during aerobic exercise. J Physiol 2006; 571: 201-10

16 [18] Horn CC, Ji H, Friedman MI. Etomoxir, a fatty acid oxidation inhibitor, 17 increases food intake and reduces hepatic energy status in rats. Physiol Behav 2004; 81: $18 \quad 157-62$

19 [19] Horowitz JF, Klein S. Lipid metabolism during endurance exercise. Am J 20 Clin Nutr 2000; 72: 558S-63S

21 [20] Inoue K, Yamazaki H, Manabe Y, Fukuda C, Hanai K, Fushiki T. 22 Transforming growth factor-beta activated during exercise in brain depresses 23 spontaneous motor activity of animals. Relevance To central fatigue. Brain Res 1999; 24

25 [21] Ishikawa T, Mizunoya W, Shibakusa T, Inoue K, Fushiki T. Transforming 26 growth factor-beta in the brain regulates fat metabolism during endurance exercise. Am 27 J Physiol Endocrinol Metab 2006; 291: E1151-9

28 [22] Kondou H, Mushiake S, Etani Y, Miyoshi Y, Michigami T, Ozono K. A 29 blocking peptide for transforming growth factor-betal activation prevents hepatic 30 fibrosis in vivo. J Hepatol 2003; 39: 742-8

31 [23] Langhans W, Scharrer E. Evidence for a vagally mediated satiety signal 32 derived from hepatic fatty acid oxidation. J Auton Nerv Syst 1987; 18: 13-8

33 [24] Li ET, Anderson GH. A role for vagus nerve in regulation of protein and 
1 carbohydrate intake. Am J Physiol 1984; 247: E815-21

2 [25] Li MX, Yoshida G, Horiuchi M, Kobayashi K, Saheki T. Prolonged effect of 3 single carnitine administration on fasted carnitine-deficient JVS mice regarding their 4 locomotor activity and energy expenditure. Biochim Biophys Acta 2006; 1761: 1191-9

5 [26] Lutz TA, Diener M, Scharrer E. Intraportal mercaptoacetate infusion increases 6 afferent activity in the common hepatic vagus branch of the rat. Am J Physiol 1997; 7 273: R442-5

8 [27] Matsumura S, Shibakusa T, Fujikawa T, Yamada H, Inoue K, Fushiki T. 9 Increase in transforming growth factor-beta in the brain during infection is related to 10 fever, not depression of spontaneous motor activity. Neuroscience 2007; 144: 1133-40

11 [28] Matsumura S, Saitou K, Miyaki T, Yoneda T, Mizushige T, Eguchi A, 12 Shibakusa T, Manabe Y, Tsuzuki S, Inoue K, Fushiki T. Mercaptoacetate inhibition of 13 fatty acid beta-oxidation attenuates the oral acceptance of fat in BALB/c mice. Am $\mathbf{J}$ 14 Physiol Regul Integr Comp Physiol 2008; 295: R82-91

15 [29] Morton GJ, Cummings DE, Baskin DG, Barsh GS, Schwartz MW. Central 16 nervous system control of food intake and body weight. Nature 2006; 443: 289-95

17 [30] Ritter S, Taylor JS. Vagal sensory neurons are required for lipoprivic but not 18 glucoprivic feeding in rats. Am J Physiol 1990; 258: R1395-401

19 [31] Ritter S, Dinh TT. 2-Mercaptoacetate and 2-deoxy-D-glucose induce Fos-like 20 immunoreactivity in rat brain. Brain Res 1994; 641: 111-20

21 [32] Ritter S, Hutton B. Mercaptoacetate-induced feeding is impaired by central 22 nucleus of the amygdala lesions. Physiol Behav 1995; 58: 1215-20

23 [33] Romijn JA, Coyle EF, Sidossis LS, Zhang XJ, Wolfe RR. Relationship 24 between fatty acid delivery and fatty acid oxidation during strenuous exercise. J Appl Physiol 1995; 79: 1939-45

[34] Rossi R, Geronimi M, Gloor P, Seebacher MC, Scharrer E. Hyperpolarization of the cell membrane of mouse hepatocytes by fatty acid oxidation. Physiol Behav 1995; 57: 509-14

29 [35] Scharrer E, Langhans W. Control of food intake by fatty acid oxidation. Am J 30 Physiol 1986; 250: R1003-6

31 [36] Schwartz MW, Woods SC, Porte D, Jr., Seeley RJ, Baskin DG. Central 32 nervous system control of food intake. Nature 2000; 404: 661-71

33 [37] Soya H, Mukai A, Deocaris CC, Ohiwa N, Chang H, Nishijima T, Fujikawa T, 
1 Togashi K, Saito T. Threshold-like pattern of neuronal activation in the hypothalamus

2 during treadmill running: establishment of a minimum running stress (MRS) rat model.

3 Neurosci Res 2007; 58: 341-8

4 [38] Torlinska T, Rutkowska D, Hryniewiecki T, Paluszak J. In vivo effect of

5 2-deoxy-D-glucose on adenine nucleotide levels in the liver and skeletal muscle of rats.

6 Acta Physiol Pol 1990; 41: 76-84

7 [39] Unsicker K, Flanders KC, Cissel DS, Lafyatis R, Sporn MB. Transforming

8 growth factor beta isoforms in the adult rat central and peripheral nervous system.

9 Neuroscience 1991; 44: 613-25

10 [40] Uyama N, Geerts A, Reynaert H. Neural connections between the 11 hypothalamus and the liver. Anat Rec A Discov Mol Cell Evol Biol 2004; 280: 808-20

12 [41] Wick AN, Drury DR, Nakada HI, Wolfe JB. Localization of the primary 13 metabolic block produced by 2-deoxyglucose. J Biol Chem 1957; 224: 963-9

14 [42] Yamazaki H, Arai M, Matsumura S, Inoue K, Fushiki T. Intracranial 15 administration of transforming growth factor-beta3 increases fat oxidation in rats. Am $\mathbf{J}$ 16 Physiol Endocrinol Metab 2002; 283: E536-44

17 [43] Yoshida G, Li MX, Horiuchi M, Nakagawa S, Sakata M, Kuchiiwa S, 18 Kuchiiwa T, Jalil MA, Begum L, Lu YB, Iijima M, Hanada T, Nakazato M, Huang ZL, 19 Eguchi N, Kobayashi K, Saheki T. Fasting-induced reduction in locomotor activity and 20 reduced response of orexin neurons in carnitine-deficient mice. Neurosci Res 2006; 55: $21 \quad 78-86$

22 [44] Yu Q, Stamenkovic I. Cell surface-localized matrix metalloproteinase-9 23 proteolytically activates TGF-beta and promotes tumor invasion and angiogenesis.

24 Genes Dev 2000; 14: 163-76 


\section{Figure Legends}

2 Fig. 1. Effect of intraperitoneal (i.p.) administration of energy metabolism inhibitors

3 [mercaptoacetate (MA) and 2-deoxyglucose (2-DG)] on spontaneous motor activity

4 (SMA). SMA over 60 minutes was determined $2 \mathrm{~h}$ after i.p. administration of MA

5 (400 $\mu \mathrm{mol} / \mathrm{kg} \mathrm{B.W.;} \mathrm{A} \mathrm{and} \mathrm{C)} \mathrm{and} \mathrm{2-DG} \mathrm{(400} \mathrm{mg/kg} \mathrm{B.W.;} \mathrm{B} \mathrm{and} \mathrm{D).} \mathrm{An} \mathrm{identical}$

6 volume of saline was administered to animals in the control group. (A) and (B) show

7 time course changes in SMA. (C) and (D) show cumulative SMA values from 0 to 60

8 min. Values are mean \pm S.E.M. $(\mathrm{n}=13-14) .(* * *, \mathrm{P}<0.001 ; * *, \mathrm{P}<0.01$ by Student's

$9 \quad t$ test)

11 Fig. 2. Effect of i.p. administration of energy metabolism inhibitors on transforming

12 growth factor-beta (TGF-beta) levels in the cerebrospinal fluid (CSF). CSF was

13 collected $2 \mathrm{~h}$ after i.p. administration of MA (400 $\mu \mathrm{mol} / \mathrm{kg}$ B.W.; A) or 2-DG (400

$14 \mathrm{mg} / \mathrm{kg}$ B.W.; B). An identical volume of saline was administered to animals in the

15 control group. The average relative luminescence units (RLU) value in the control

16 group was defined as $100 \%$. Values are mean \pm S.E.M. $(\mathrm{n}=12-14) .(*, \mathrm{P}<0.05$ by 
1 Student's t-test)

2

3 Fig. 3. Effect of intracisternal (i.c.) administration of anti-TGF-beta or non-immune

4 control antibodies $(5 \mu \mathrm{g}$ dissolved in $10 \mu \mathrm{L})$ on SMA after i.p. administration of energy

5 metabolism inhibitors MA (400 $\mu \mathrm{mol} / \mathrm{kg} \mathrm{B.W.;} \mathrm{A)} \mathrm{and} \mathrm{2-DG} \mathrm{(400} \mathrm{mg/kg} \mathrm{B.W.;} \mathrm{B).} \mathrm{An}$

6 identical volume of saline was administered i.p. to control animals. SMA cumulative

7 values over $1 \mathrm{~h}$ were determined $2 \mathrm{~h}$ after the i.c. and i.p. administrations. Values are

8 mean \pm S.E.M. $(\mathrm{n}=6-8) .\left(* *, \mathrm{P}<0.01{ }^{*}, \mathrm{P}<0.05\right.$ by two-way ANOVA, followed by

9 one-way ANOVA and post-hoc Tukey's multiple comparison test (A) and two-way

10 ANOVA followed by Student's $t$ test to identify which group differences accounted for

11 the significant $\mathrm{P}$ value $(\mathrm{B}))$

13 Fig. 4. Effect of vagotomy on SMA after i.p. administration of the energy metabolism

14 inhibitors MA (400 $\mu \mathrm{mol} / \mathrm{kg} \mathrm{B.W.;} \mathrm{A)} \mathrm{and} \mathrm{2-DG} \mathrm{(400} \mathrm{mg/kg} \mathrm{B.W.;} \mathrm{B).} \mathrm{An} \mathrm{identical}$

15 volume of saline was administered i.p. to control animals. SMA cumulative values over

$161 \mathrm{~h}$ were determined $2 \mathrm{~h}$ after i.p. administration. Values are mean \pm S.E.M. $(\mathrm{n}=7-8)$. 
$1 \quad(* *, \mathrm{P}<0.01 ; *, \mathrm{P}<0.05$ by one-way ANOVA, followed by a post-hoc Tukey's

2 multiple comparison test.)

3

4 Fig. 5. Effect of vagotomy (A) and sham surgery (B) on TGF-beta levels in the CSF $2 \mathrm{~h}$

5 after i.p. administration of MA (400 $\mu \mathrm{mol} / \mathrm{kg} \mathrm{B.W.).} \mathrm{An} \mathrm{identical} \mathrm{volume} \mathrm{of} \mathrm{saline} \mathrm{was}$

6 administered to animals in the control group. The average RLU value in control groups

7 was defined as $100 \%$. Values are mean \pm S.E.M. $(n=12-14) .(*, P<0.05$ by Student's

$8 \quad t$ test)

9

10 


\section{A}

C
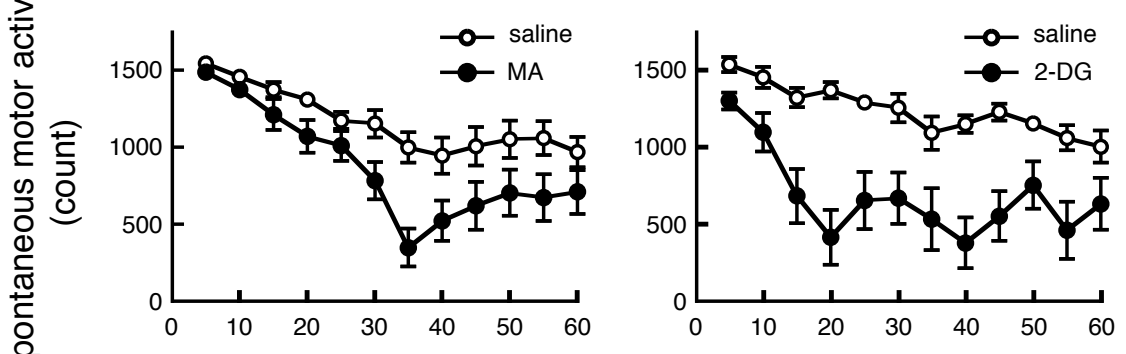

time (min.)
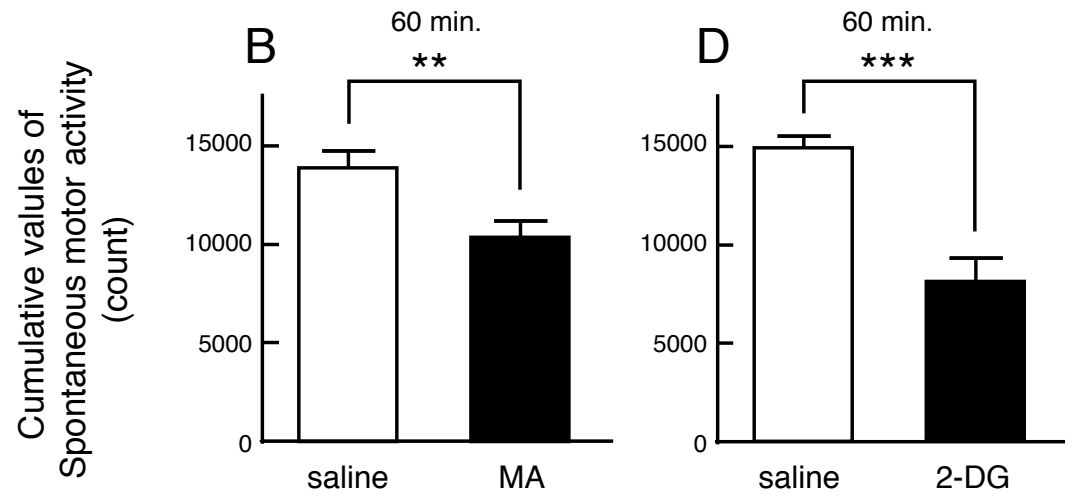

Figure 1 

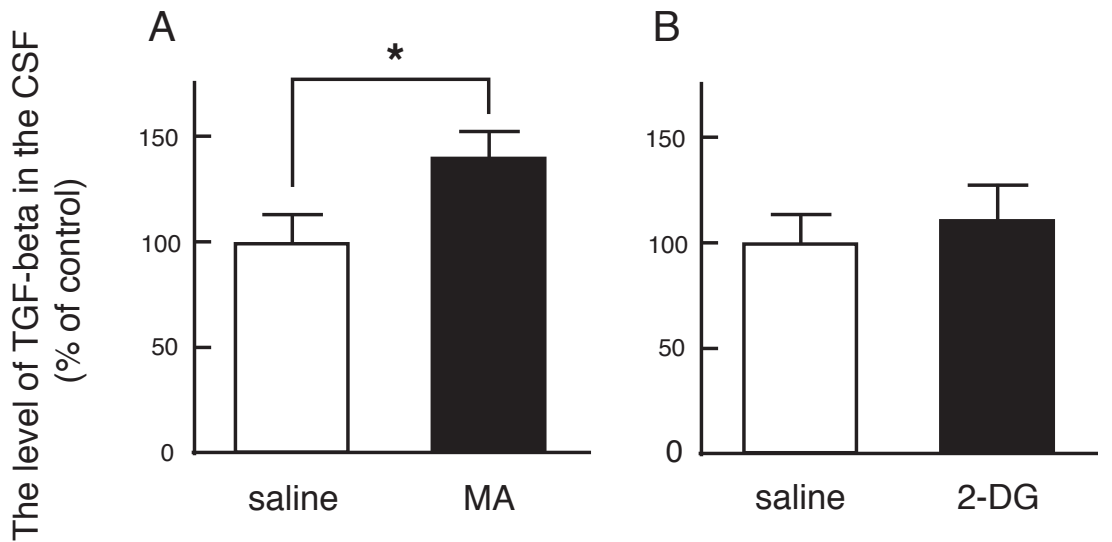

Figure 2 
京都大学

A

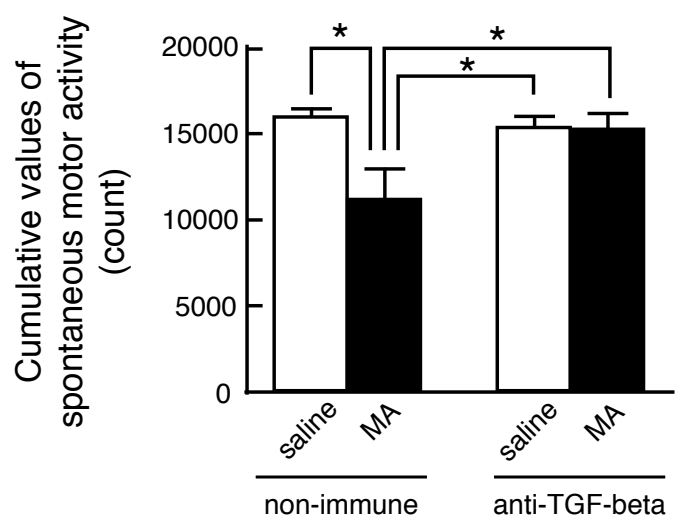

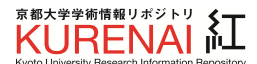

B

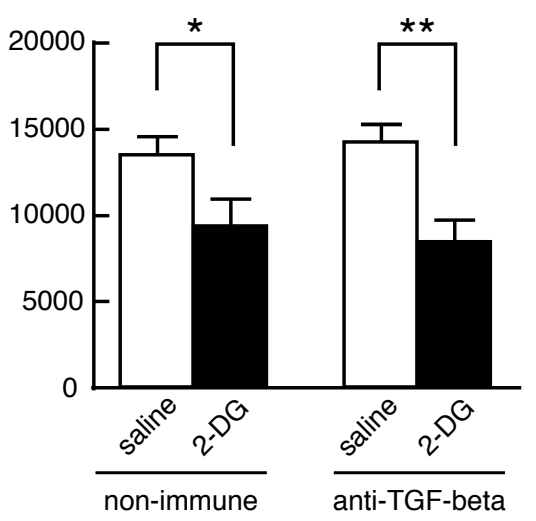

Figure 3 

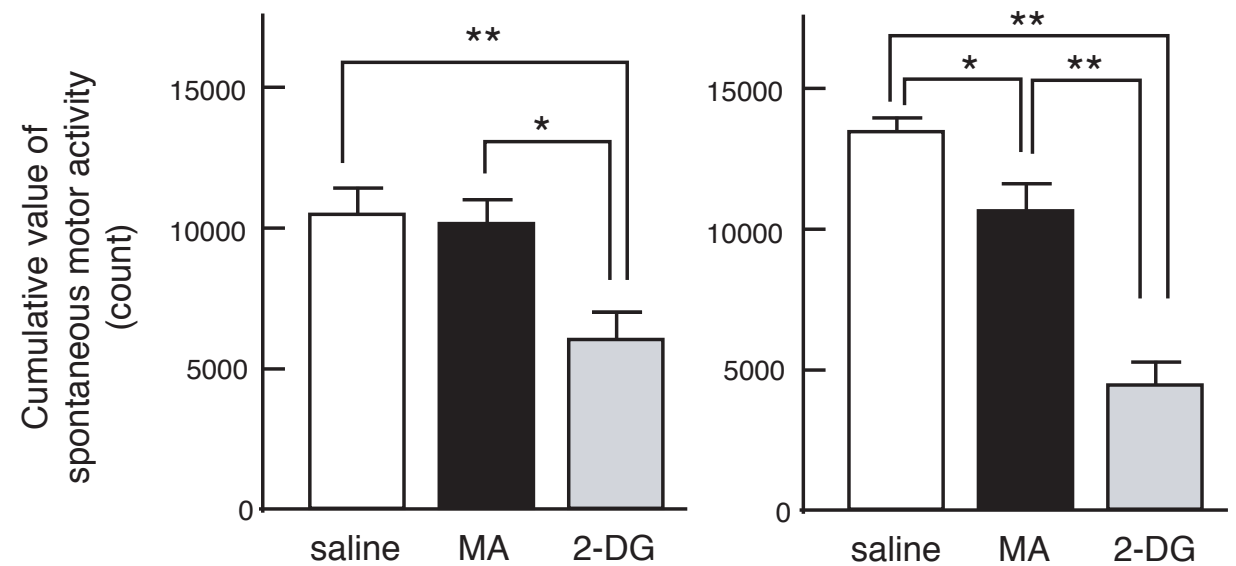

Figure 4 


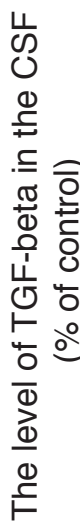

A

vagotomy

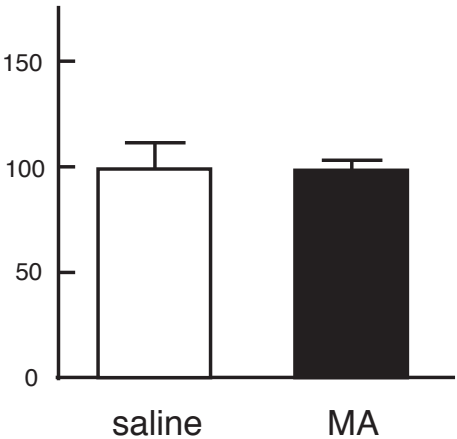

B

sham

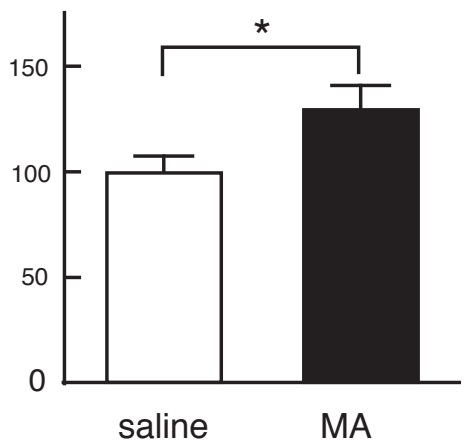

Figure 5 
$1 \quad$ Supplementary Figure 1

2

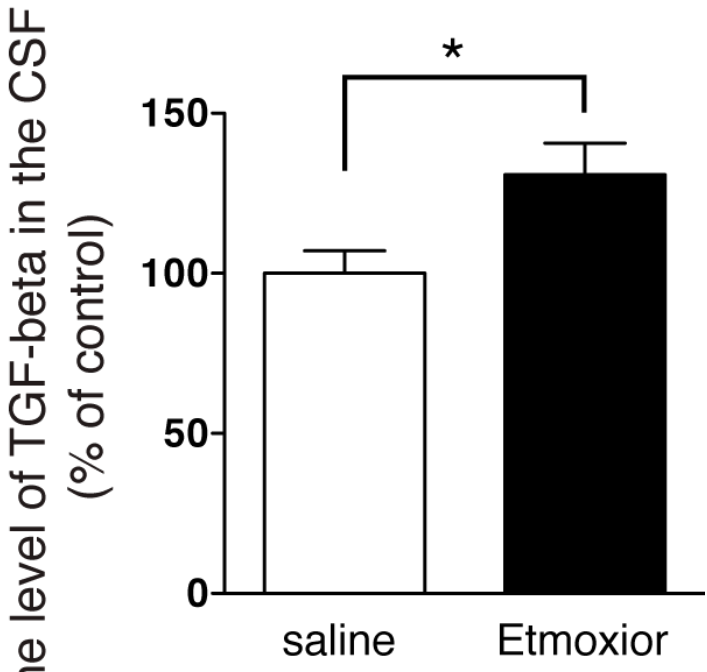

\section{Legend}

10 Supplementary Figure 1. Effect of i.p. administration of etomoxior on TGF-beta level in

11 the CSF. CSF was collected $2 \mathrm{~h}$ after i.p. administration of etomoxior ( $25 \mathrm{mg} / \mathrm{kg} \mathrm{B}$.W.)

12 An identical volume of saline was administered to animals in the control group. The

13 average relative luminescence units (RLU) value in the control group was defined as

14 100\%. Values are mean \pm S.E.M. $(\mathrm{n}=6-7) . \quad(*, \mathrm{P}<0.05$ by Student's t-test $)$

\section{Materials \& Methods}

17 Etomxior was purchased from Sigma Aldrich Japan (Tokyo, Japan). Etomoxir was

18 dissolved in sterile saline (Otsuka Pharmaceutical, Tokyo, Japan). Saline was used as

19 control. Other protocols are described in Materials \& Methods section in article. 